\title{
PEMAHAMAN KONSEP BERMAIN SISWA MOTORIK TINGGI DAN RENDAH DENGAN MODEL PEMBELAJARAN TEACHING GAME for UNDERTANDING (TGfU)
}

\author{
Y. Touvan Juni Samodra \\ Pendidikan Kepelatihan Olahraga, Fakultas Keguruan dan IImu Pendidikan \\ Universitas Tanjungpura, Pontianak, Indonesia \\ Email : tovan@fkip.untan.ac.id
}

\begin{abstract}
ABSTRAK
Pendidikan jasmani dipahami sebagai pendidikan melalui gerak dan tentang gerak. Melalui gerak dipahami siswa dididik dengan media gerak, pembelajaran tentang gerak merupakan ranah kognisi untuk memahami gerak yang dipelajari. Gerak merupakan sajian utama yang dipergunakan dalam pendidikan. Kegiatan bermain merupakan aktivitas yang disenangi dalam pendidikan jasmani. Agar dapat berpartisipasi dalam permainan selain keterampilan gerak sebagai modal dasar, tidak kalah penting adalah pemahaman terhadap permainan. Pemahaman ini akan memberikan bakal untuk peserta didik memutuskan apakah akan bergerak, kemana bergerak, dengan gerakan apa, atau bahkan memutuskan untuk tidak bergerak. Penelitian ini focus pada bagaimana pengaruh intervensi model pembelajaran Teaching Game for Understanding (TGfU) terhadap pemahaman konsep bermain pada siswa sekolah dasar. Penelitian dilakukan dengan eksperimen dengan membandingkan kemampua dua kelompok eksperiman. Sampel adalah siswa sekolah dasar yang memiliki kemampuan perspsi tinggi 10 rendah masing masing 10 siswa. Instrument penelitian adalah lembar pengamatan Game performance Assesment Instrumen (GPAI), tes persepsi motorik. Data dianalisis dengan menggunakan $U j \mathrm{ji}$ T. Hasil penelitian menunjukkan siswa yang memiliki perspsi motorik tinggi dan rendah sama hasilnya dalam pemahaman konsep bermain.
\end{abstract}

Kata kunci: TGfU, Persepsi Motorik, GPAI

\begin{abstract}
Movement was implemented in physical education. Movements were media for educated students, so movements are used in education process as media. Learning about movement was the way cognition to understand how the movement did. So movements were the main subject in process education. Playing were activities that enjoyed by students in physical education. In order to take participation in game, fundamental movement were the basic skill used to master and second understanding the rule of the game. Tactical understanding in game performance will gave students know how to decide movement, where have to, and what kind of movement should do. Focus of this study on effect of teaching game for understanding on understanding concept of play in primary school students. Research design by experiment two group's posttest only. Sample whereby 4-6 grader elementary school 10 students with high perceptual motor and 10 low. GPAl
\end{abstract}


used for data collection. Data were analyzed with independent sample T test. Result study showed students wht high and low perceptual motor had the same result in understanding the concept of game. Students withw higt perceptual motor have better score.

Keywords: TGfU, pereceptual motor, GPAI

\section{PENDAHULUAN}

Pemahaman konsep bermain dapat dimanifestasikan dalam beberapa hal. Pertama penguasaan terhadap pengetahuan, kedua penguasaan terhadap keterampilan, ketiga penguasaan terhadap strategi dan taktik, keempat penguasaan terhadap peraturan permainan, dan kelima penguasan terhadap konteks permainan. Pemain yang hebat adalah pemain yang menguasai dan mampu memutuskan kelima elemen tersebut serta menyelesaikan kasus (konteks) dengan hasil yang menguntungkan bagi team.

Pemahaman konsep bermain merupakan modal dasar yang harus selalu dikembangkan. Pemahaman konsep bermain ini merupakan gabungan antara penerapan teknik yang dimiliki, pemahaman terhadap peraturan, dan pemahaman kesadaran posisi, dan pemahaman untukpengambilan keputusan berdasarkan situasi yang selalu berubah. Penelitian membuktikan bahwa ada perbedaan dalam pengambilan keputusan antar pemain yang berpengalaman dengan pemain pemula (Mitchell, 2011). Perbedaan ini terutama salah satunya disebabkan pengalaman jam terbang pemain. Pengalaman bermain merupkan kunci pokok yang menyebabkan perbedaan yang besar. Sehingga dalam olahraga prestasi latih tanding harus dilakukan untuk memperbesar pengalaman dalam pengambilan keputusan yang sifatnya kritis.

Bagaimana caranya mengetahui Pemahaman konsep bermain ini? Beberapa penelitian telah dilakukan kaitan dengan hal ini, ada yang menggunakan tes pengetahuan, hal ini dengan cara menantakan kepada atlet dan pelatih dengan angket, wawancara, observas langsung atau tidak langsung (Bohler, 2011)(Griffin, L. L., Dodds, P., Placek, J. H., \& Tremino, 2001). Beberapa penelitian terdahulu melakukan pengamatan secara tidak langung dengan dibantu dengan rekaman video, prosedur yang dilakukan adalah dengan merekam atlet bermain kemudian peneliti melakukan pengamatan rekaman video setelah permainan selesai di lain waktu dipandu dengan lembar pengamatan (French, K. E.; Werner, P. H.; Taylor, K.; Hussey, K.; Jones, 1996) (Rink, J. E., French, K. E., \& Graham, 1996) (French, K. E., \&Thomas, 1987).

Dalam penelitian ini dipergunakan permainan field game. Permainan ini masih sederhana dan dimodifikasi sampai menjadi permainan yang sangat aman untuk siswa sekolah dasar. Lapangan berbentuk sama seperti lapangan softball dengan ukuran panjang setiap sisi 10 meter. Bola diganti dengan bola plastic (mempertimbangkan tingkat keamanan). Aturan cukup sederhana, pertama bola dilempar oleh pelempar, pemain penyerang menendang bola yang dilemparkan, kemudian berlari mengelilingi setiap base (4 base sampai home) dan berusaha tidak dimatikan oleh tim penjaga. Kedua setiap base hanya boleh ditempati oleh satu orang. Ketiga jumlah pemain 10 orang. Keempat aturan pergantian adalah setelah semua pemain melakukan tendangan berapapun yang mati belum berganti posisi (penyerang ke bertahan) sebelum semua tim 
menendang. Kelima setiap base jika bisa dicapai memiliki skor 1 jika home run maka nilai 6. Ketujuh, pemain penjaga berusaha mematikan lawan dengan cara menyentuhkan bola ke base arah yang dituju atau menyentuhkan bola ke pelari yang menuju base. Permainan ini adalah hasil dari penelitian tersendiri yang dilakukan peneliti.

Modifikasi permainan ini dapat mengembangakan ketermpilan jalan, lari, lompat, lempar, memukul. Kemampuan bermain yang dapat dikembangkan adalah bagaimana menciptakan peluang agar mendapatkan point (mengarahkan tendangan, kapan harus lari, kerjasama menyelamatkan tim, memahami posisi, ketepatan timing untuk berpindah atau tidak berpindah base). Bagi pemain bertahan bagaiman upaya untuk mencegah pemain lawan ke base selanjutnya, bagaimana mematikan penendang? Membutuhkan bola dilempar ke kawan atupun dibawa sendiri untuk mematikan lawan, koordinasi kerjasama antar anggota tim. Modifikasi ini aman dan kontak fisik cenderung dapat dikurangi.

Ternyata variabel ketermpilan gerak dasar juga merupakan salah satu keberhasilan dalam melakukan permainan dalam olahraga (handball) semakin tinggi keterampilan gerak dasar akan mempengaruhi terhadap kemampuan konsep bermain (Fadilah \& Wibowo, 2018) Kaitannya dengan hal ini maka untuk dapat bermain minimal siswa harus memiliki kemampuan berjalan, berlari, melempar, menendang. Kemampuan berikutnya adalah pemahaman peraturan.

Dari sisi keterampilan siswa sekolah dasar kelas rendah sudah dapat melakukan, dari sisi peraturan permainan ini cukup sederhana dan mudah untuk dipahami. Dalam penelitian ini menggunakan siswa kelas atas (4-6) sebagai orang coba. Fokusnya adalah bagaimana pemahaman konsep bermain siswa dengan mempertimbangkan kemampuan persepsi motorik tinggi dan motorik rendah. Variabel berikutnya adalah intervensi model pembeajaran TGfU. Model pembelajaran ini sudah lama dikenal tetapi tidak banyak orang yang memahami bagaimana aplikasi di lapangan. Beberapa hasil penelitian memberikan gambaran tentang model pembelajaran ini, salah satunya adalah penelitian yang dilakukan di Australia tahun 2011 TGfU dijadikan sebagai kurikulum sekolah untuk pendidikan jasmani, berdasarkan survey yang dilakukan pada tahun tersebut dinyatakan bahwa meskipus TGfU sudah dikenalkan hasilnya ternyata guru-guru belum sepenuhnya paham dengan bagaimana pengimplementasiannya (Pill, 2011).

Penelitian berikutnya menanyakan kaitan dengan TGfU ini yang juga dipertanyakan oleh peneliti (Memmert et al., 2015) 1) bagaimana pendekatan saintifik dari berbagai disiplin ilmu dapat dipergunakan untuk penguatan game dan permainan bagi pemula 2) bagaimana pendekatan saintitif dipergunakan untuk menguatkan permainan. Bagaimana caranya penggunaan pemikiran yang komplek dipergunakan dalam pendidikan jasmani dan kepelatihan. Bagaimana bisa dengan pendesainan game dapat membantu dalam proses pembelajaran. Bagaimana menyusun desain permainan yang dapat menciptakan pemahakan taktik, pengembangan keterampilan dalam pembelajaran yang melibatkan kognisi. Bagaimana caranya guru dapat mengambil keuntungan dengan model TGfU.

Diragukan bahwa pendekatan TGfU dapat mengembangkan kemampuan kognitif, afektif, psikomotor dan budaya. Penelitian yang membandingkan antara model drill dengan TGfU memberikan gambaran bahwa kedua kelompok mengalami peningkatan terhadap kemampuanteknik, yang menjadi perbadaan adalah kelompok yang latihan dengan TGfU mengalami peningkatan yang pesat pada pengambilan keputusan 
untuk bergerak baik ketika sedang memegang bola ataupun tidak sedang memegang bola (Gray \& Sproule, 2011). Penelitian sama juga membandingkan drill dengan TGfU terhadap hasil kognitif dalam kontek permainan, hasil penelitian menyatakan bahwa TGfU signifikan meningkakan kemampuan pemahaman dalam pengambilan keputusan pada cabang olahraga handball (Balakrishnan, Rengasamy, \& Aman, 2011).

Beberapa penelitian di atas memberikan keterangan bahwa polemik penggunaan TGfu masih terjadi, bukti bahwa penelitian TGfU memberikan hasil positif juga tersedia. Harapannya penelitian ini memberikan sumbangan positif pembuktian TGfU terhadap konsep kemampuan bermain dalam olahraga yang sederhana yang dimodifikasi untuk sekolah dasar. Penelitian ini mencoba untuk membantu menjawab pertanyaan apakah TGfU dapat diterapkan di sekolah dasar (Memmert et al., 2015). Meskipun telah dilaksanakan ternyata hasilnya guru sendiri masih belum memahami sepenuhnya (Pill, 2011).

\section{METODE PENELITIAN}

$\begin{array}{ccc}\begin{array}{c}\text { Penelitian dilakukan } \\ \text { eksperimen } \\ \text { dengan }\end{array} \text { presedur } & \text { dengan }\end{array}$ memberikan perlakuan dan post test, tanpa pre test. Dalam penelitian ini tidak ada pre test, karena siswa dipastikan belum bisa permainan yang dilakukan kerena permainan yang dipergunakan untuk penelitian dikembangkan sendiri oleh peneliti. Populasi adalah siswa sekolah dasar 40 siswa, yang di tes kemampuan persepsi motorik. 10 tertinggi diklasifikasikan dalam kelompok tinggi dan 10 terendah dalam kelompok persepsi motorik rendah.
Setelah terdapat dua kelompok kemudian kedua kelompok diberi treatment TGfU dengan permainan field game yang telah dimodifikasi. TGfU yang dipergunakan adalah jenis game, teach, game. Diakhir pertemuan kedua kelompok ini dipertandingkan dan di rekam dengan video untuk kemudian diamati oleh 3 orang berdasarkan lembar observasi sesuai instrument GPAl pada tabel 1. Penggunaan GPAI ini ternyata telah dipergunakan oleh banyak peneliti (Javier Aguilar Sánchez, Tamayo, \& Ríos, 2016). Peneliti melakukan validasi instrument GPAI dengan mencobakan pada bola volley, isi instrument tersebut untuk mengevaluasi pengambilan keputusan altet (Conejero Suárez, Claver Rabaz, Fernández-Echeverría, GonzálezSilva, \& Moreno Arroyo, 2017)

Dalam tabel 1 terdapat beberapa istilah dalam tabel yang dapat diterangkan sebagai berikut:

1. Teknik dasar: pemain menunjukkan penggunaan teknik dasar dalam bermain (melempar, menangkap, menendang, berlari antar base).

2. Back up: pemain membantu pemain di lapangan untuk menjaga base jika ada pemain lapangan sedang mengambil bola.

3. Penempatan posisi: pemain memahami dan dapat melaksanakan menempatkan diri dan ketika bertahan ataupun menyerang untuk keuntungan team.

4. Pengambilan keputusan: pemain bermain dengan baik, tergantung dari situsi (contoh, jika tidak ada pelari di base, belum ada yang mati maka bola harus dilempar ke base I) 
Tabel 1. Intsrumen GPAI

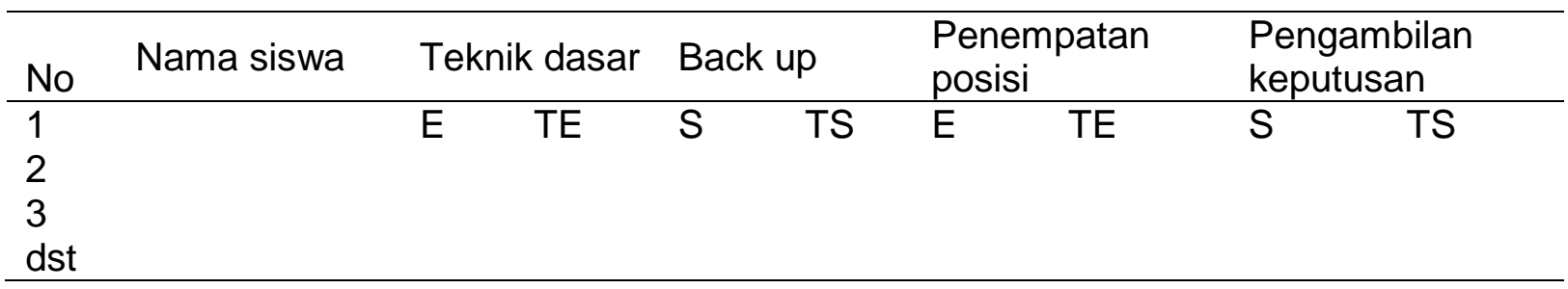

Ket: E: Efisien, TE: Tidak Efisien, S: sesuai, TS: tidak sesuai

RUmus perhitungan GPAI sebagai berikut:

GPAI = pengambilan keputusan+indek melakukan tindakan + indek pemberian bantuan/support/back up) dibagi dengan tiga (3) dikalikan (jumlah indek indek yang dilakukan) (Metzle, 2000). Nilai GPAI setiap siswa kemudian dianalisis untuk melihat perbedaaan kedua kelompok. Uji yang dipergunakan untuk melihat beda dengan Uji T independent sample T test.

\section{HASIL DAN PEMBAHASAN}

Hasil Penelitian

Sebelum Penelitian dilakukan terhadap siswa kelas 4-6 kelas . Deskripsi hasil GPAI sebagai berikut:

Tabel 2. Deskripsi hasil GPAI

\begin{tabular}{llrr}
\hline Keterangan & Persepsi Tinggi & \multicolumn{2}{c}{ Persepsi Rendah } \\
sampel & 10 & 5.4792 & 10 \\
Mean & & 5.3125 & 3.8813 \\
Median & & 1.45207 & 3.7438 \\
Standar deviasi & & 1.55045 \\
\hline
\end{tabular}

Hasil penelitian dilihat dari rerata terdapat perbedaan hasil, kelompok persepsi tinggi nilai rerata 5.47 dan kelompok dengan persepsi rendah 3.88 dengan standar deviasi yang tidak jauh berbeda. Berikutnya uji normalitas, diperoleh hasil sebagai berikut:

Tabel 3. Uji normalitas

\begin{tabular}{|c|c|c|c|}
\hline \multirow[t]{2}{*}{ Keterangan } & \multicolumn{3}{|l|}{ Kolmogorov-Smirnov $^{a}$} \\
\hline & statistik & $\mathrm{df}$ & Sig. \\
\hline Persepsi tinggi & .276 & 10 & .029 \\
\hline Persepsi rendah & .272 & 10 & .035 \\
\hline
\end{tabular}

Nilai signifikasni dibawah 0,05 maka dapat disimpulkan data berdistribusi normal. Selanjutnya adalah Uji T sampel bebas. Hasil perhitungan dengan SPSS sebagai berikut: 
Tabel 4. Hasil analisis Uji beda

\begin{tabular}{rlrr}
\hline & & $\begin{array}{c}\text { Equal variances } \\
\text { assumed }\end{array}$ & $\begin{array}{c}\text { Equal variances } \\
\text { not assumed }\end{array}$ \\
\hline Levene's Test for & $\mathrm{F}$ & .938 & \\
Equality of Variances & Sig. & .346 & \\
& $\mathrm{t}$ & 2.379 & 2.379 \\
& $\mathrm{df}$ & 18 & 17.923 \\
& Sig. (2-tailed) & .029 & .029 \\
\hline
\end{tabular}

Dilihat dari hasil Levene's test diperoleh hasil $\mathrm{F}=.938 \quad(\mathrm{sig}=0.346)$ karena sig di atas 0,05 maka dapat disimpulkan data homogen. Pada Uji T dapat dilihat Sig. hitung 0.029, karena sig. lebih kecil dari sig. kreteria 0.05 maka dapat dinyatakan terdapat perbedaan hasil pemahaman konsep bermain antara kedua kelompok.

\section{Pembahasan Hasil Penelitian}

Berdasarkan hasil penelitian dipahami bahwa kemampuan persepsi motorik menentukan hasil belajar pemahaman konsep bermain, dibuktikan dengan nilai rerata capaian pembelajaran 5.47 untuk siswa dengan persepsi motorik tinggi dan 3.88 untuk siswa dengan persepsi motorik rendah. Yang menjadi catatan disini adalah persepsi motorik ternyata mempengaruhi dalam proses belajar. Belajar disini bukan hanya saja belajar gerak tetapi juga belajar memahami konsep. Konsep yang dimaksudkan dalam penelitian ini adalah kesadaran untuk bermain dan menempatkan diri pada posisiyang tepat. Apakah harus bergerak atau tidak bergerak, mengumpan atau membawa bola sendiri. Proses pengambilan keputusan yang dilakukan hanya dalam waktu yang sangat singkat, salah dalam pengambilan keputusan maka akan mati (jika sebagai penyerang) dan lawan akan mencetak skor (jika sebagai bertahan). Bahwa penelitian ini memberikan hasil yang berbeda dengan melihat variabel persepsi motorik, dapat disimpulkan bahwa model TGfU dapat dipergunakan di Sekolah dasar. Penelitian lain memberikan bukti bahwa kemampuan meta kognisi meningkat terhadap anak usia 11-12 tahun dengan dilakukan intervensi TGfU dalam permainan bola volley (Chatzipanteli, Digelidis, Karatzoglidis, \& Dean, 2016). Hal ini memberikan bukti bahwa dengan penggunaan model pembelajaran ini meningkatkan kemampuan kognisi tidak terkecuali terhadap siswa sekolah dasar. Sekolah menerapkan pembelajaran pendidikan jasmani dengan TGfU, berdasarkan temuan penelitian ternyata semua tim mendapat capaian yang lebih baik di akhir program (Dania, Zounhia, \& Kossiva, 2016). TGfU dilakukan terhadap siswa sekolah dasar juga mengalami pengaruh yang positif (Erland, Sucipto, \& Budiman, 2018). Latihan taktik yang dilaksanakan di sekolah dasar sudah dapat dilakukan, hal ini dibuktikan dengan penelitian yang menyatakan bahwa dengan latihan volley anak umur 11 tahun sudah dapat memahami bagaimana seharusnya bermain bola volley yang dinilai dengan GPAI (Macías-Romero \& Otero-Saborido, 2018).

Pemikiran tentang TGfU untuk olahraga permainan sebagai catatan pertama model pembelajaran ini jauh melampui tentang taktik lebih jauh adalah pemahaman terhadap permainan itu sendiri kedua, pemahaman terhadap permainan akan mengajarkan/melatihkan permainan itu sendiri (Almond, 2015). Penelitian lain memberikan gambaran TGfU dapat meningkatkan kemampuan bermain, motivasi dan pengalaman afektif yang positif (Light \& Harvey, 2017). TGfU memberikan kesempatan kepada siswa 
untuk berfikir dan bergerak sesuai dengan kebutuhan. Didiikan cara melakukan penyesuaian diri terhadap perubahan permainan, bukan hanya menghafalkan pola yang sudah diajarkan. Peningkatan kemampuan untuk menempatkan diri baik bertahan dan menyerang serta memberikan dukungan serta penguasaan daerah jauh lebih bagus dikembangkan. Penelitian yang membandingkan TGfU dan Drill, membuktikan bahwa pemain hokey junior TGfU hasilnya lebih bagus pada pemain Malaysia, tetapi berkebalikaan dengan pemain India (Nathan, 2017). Terhadap kenaikan denyut nadi, ternyata TGfU lebih tinggi dibandingkan dengan drill (Nathan, 2017) $\mathrm{Hal}$ ini memberikan keterangan bahwa model pembelajaran ini intensitasnya lebih tinggi dibandingkan dengan drill. Penelitian lain memberikan bukti kedua bahwa model TGfU akan meningkatkan kemampuan pengambilan keputusan, eksekusi, keterlibatan dalam permainan, pengetahuan permainan, kesenangan bermain, capaian kompetensi dan keinginan untuk selalu latihan (MoralesBelando \& Arias-Estero, 2017).

Lebih lanjut kaitan dengan penerapan model pembelajaran TGfU, masih sangat sedikit. Model pembelajaran ini memancing guru dan siswa agar proses pembelajaran selalu menentukan apa dan bagaimana sebuah tugas diseslesaikan, pemberian umpan balik, keterlibatan aktif dari pelatihn dan atlet (Morales-Belando \& Arias-Estero, 2017). Sesi positif model pembelajaran ini adalah keterlibatan semua orang yang terlibat, guru, siswa, atau pelatih dan atlet. Pembelajaran atau latihan dilakukan karena memang diperlukan, latihan dilakukan karena untuk menutupi kekurangan dan bagaimana menutupnya dilakukan dengan interaksi yang saling mendukug untuk pemecahan masalah secara tim. Mendesain pembelajaran dengan modifikasi dan penerapan taktikal game ternyata meningkatkan kemampuan passing, dribbling, menembak. Hal lain yang meningkat adalah sama dengan peningkatan yang terjadi pada orang dewasa yaitu penjagaan bola, bagaimana melakukan penetrasi ataupun bertahan (Serra-Olivares, García-López, \& Calderón, 2016). Salah satu ciri dari TGfU adalah adanya modifikasi, modifikasi ini dapat dilakukan terhadap ukuran lapangan, jumlah pemain, ukuran target, lamanya permainan, jumlah setiap tim. Beberapa hal tersebut dilakukan untuk meningkatkan kemampuan teknik, taktik dan trategi. Berbagai penelitian telah memberikan dukungan tentang hal ini. Terjadi perubahan yang positif dengan 8 minggu perlakuan terhadap pengambilan keputusan dengan bermain game di lapanga kecil dengan menggunakan TGfU pada olahraga futsal,hanball dan bola basket dengan sampel remaja putri yang tidak terlatih (J. Aguilar Sánchez, Hernández-Mendo, Martínez, Garrido, \& Ríos, 2018). Ternyata TGfU juga dapat dipergunakan pada olahraga layar, pelatih memberikan penekanan pada apa, bagaimana yang harus dilakukan, serta memberikan umpan balik, dan menjadi titik pengamatan adalah pengambilan keputusan, pemilihan gerak yang tepat, keterlibatan,pengetahuan, bagaimana menikmati olahrga dan keberlanjutan berlatih, terhadap semua in ternyata semua mngalami peningkatan (MoralesBelando \& Arias-Estero, 2017).

Dalam kurikulum sport education dimana pembelajaran dilakukan dengan menyerupai musih pertandingan dengan 17 sesi unit pembelajaran, ternyata model ini dapat meningkatkan kemampuan bermain termasuk pemahaman bermain (Farias, Mesquita, \& Hastie, 2015). Hal ini menjadi catatan tersendiri bagi kurikulum yang dilaksanakan. Dengan kurikulum sport education maka, kualitas penguasaan sampai internalisasi nilai nilai yang terkandung di dalam olahraga akan sangat mudah masuk ke siswa. Hal ini dapat terjadi karena siswa benar benar melakukan adat dalam setiapkecabangan yang dlakukan selama satu sampai 2 
semester. Dengan system pembelajaran ini dapat dipastikan siswa akan mengalami peningkatan yang luar biasa di bidang penguasaan ataupun pemahaman bermain. Yang menjadi permasalahan adalah apakah memunkinkan dilakukan di Indonesia dengan sudah ditetapkanya kurikulum, silabus secara nasional. Model sport education ini akan lebih berhasil jika dalam pebelajaran juga digaungkan dengan model pembelajaran TGfU. Sport education sebagai payung kegiatan TGfU sebagai proses untuk meningkatkan kemampuan siswa. Keterlibatan siswa akan tercapai denganmudh jika diwdahi dengan dua model pembelajaran ini. Lebih tajam lagi jika pertandingan atau kompetisi diselenggaraakan bukan intern sekolah tetapi bekerjasama dengan beberapa sekolah lain.

\section{PENUTUP}

\section{Simpulan}

Hasil penelitian menunjukan bahwa dengan menggunakan permainan field game yang dimodikasi, intervensi TGfU siswa yang memiliki persepsi motorik lebih tinggi hasilnya lebih tinggi terhadap pemahaman konsep bermain. Kedua TGfU dapat dipergunakan untuk proses belajar mengajar di sekolah dasar. Ketiga persepsi motorik menjadi salah satu variabel pertimbangan dalam pembelajaran.

\section{DAFTAR PUSTAKA}

Almond, L. (2015). Rethinking Teaching Games for Understanding. Agora Para La Educación Física y El Deporte.

Balakrishnan, M., Rengasamy, S., \& Aman, M. S. (2011). Effect of teaching games for understanding approach on students' cognitive learning outcome. World Academy of Science, Engineering and Technology.

https://doi.org/10.5281/zenodo.1074

\section{1}

Bohler, H. (2011). Fifth-Grade Students' Tactical Understanding, DecisionMaking and Transfer of Knowledge in a Tactical Games Model Net/Wall Sampling Unit.

Chatzipanteli, A., Digelidis, N., Karatzoglidis, C., \& Dean, R. (2016). A tactical-game approach and enhancement of metacognitive behaviour in elementary school students. Physical Education and Sport

Pedagogy. https://doi.org/10.1080/17408989.20 14.931366

Conejero Suárez, M., Claver Rabaz, F., Fernández-Echeverría, C., González-Silva, J., \& Moreno Arroyo, M. P. (2017). Design and validation of an observation instrument to assess decision making in the reception action of volleyball. Cultura_ciencia_deporte. https://doi.org/10.12800/ccd.v12i34. 833

Dania, A., Zounhia, K., \& Kossiva, I. (2016). EFFECTS OF TEACHING GAMES FOR UNDERSTANDING ON QUANTITATIVE AND QUALITATIVE INDICES OF GRADE THREE STUDENTS' GAME PERFORMANCE. In ICERI2016 Proceedings. https://doi.org/10.21125/iceri.2016.0 942

Erland, J., Sucipto, S., \& Budiman, D. (2018). Implementasi Pendekatan Taktis Terhadap Hasil Keterampilan Bermain Sepak Takraw. TEGAR: Journal of Teaching Physical Education in Elementary School. https://doi.org/10.17509/tegar.v2i1.1 3779

Fadilah, M., \& Wibowo, R. (2018). Kontribusi Keterampilan Gerak Fundamental Terhadap 
Jurnal IImu Keolahragaan Undiksha

p-ISSN : 2613-9693 | e-ISSN : 2613-9685

Volume 8 Nomor 2 Tahun 2020

Keterampilan Bermain Small-Sided Handball Games. JURNAL PENDIDIKAN JASMANI DAN OLAHRAGA.

https://doi.org/10.17509/jpjo.v3i1.76 67

Farias, C. F., Mesquita, I. R., \& Hastie, P. A. (2015). Game performance and understanding within a hybrid sport education season. Journal of Teaching in Physical Education. https://doi.org/10.1123/jtpe.20130149

French, K. E., \&Thomas, J. R. (1987). The relation of knowledge development to children's basketball performance. Journal of Sport Psychology, 9(1), 15-32. https://doi.org/https://doi.org/10.112 3/jsp.9.1.15

French, K. E.; Werner, P. H.; Taylor, K.; Hussey, K.; Jones, J. (1996). The Effects Of A 6-Week Unit Of Tactical, Skill, or Combined Tactical and Skill Instruction on Badminton Performance of Ninth-Grade Students. . . Journal of Teaching in Physical Education, 15(3), 439-463. https://doi.org/10.1123/jtpe.15.4.439

Gray, S., \& Sproule, J. (2011). Developing pupils' performance in team invasion games. Physical Education and Sport Pedagogy. https://doi.org/10.1080/1740898090 3535792

Griffin, L. L., Dodds, P., Placek, J. H., \& Tremino, F. (2001). Middle school student's conceptions of soccer: Their solutions to tactical problems. Journal of Teaching in Physical Education. Journal of Teaching in Physical Education, 20(4), 324-340.

Light, R. L., \& Harvey, S. (2017). Positive Pedagogy for sport coaching. Sport, Education and Society. https://doi.org/10.1080/13573322.20

\subsection{7}

Macías-Romero, J., \& Otero-Saborido, F. M. (2018). Effects of using an assessment instrument on procedural knowledge in team sports. Journal of Physical Education and Sport. https://doi.org/10.7752/jpes.2018.s2 151

Memmert, D., Hillmann, W., Huttermann, S., Klein-Soetebier, T., Konig, S., Nopp, S., ... Griffin, L. (2015). Top 10 research questions related to teaching games for understanding. Research Quarterly for Exercise and Sport.

https://doi.org/10.1080/02701367.20 15.1087294

Metzle. (2000). Instructional Models for Physical Education. Allyn \& Bcon. Massachusetts.

Mitchell, S. (2011). Frameworks for Diagnosing Student Performance Problems in Striking/Fielding and Target Games. Journal of Physical Education, Recreation \& Dance, 81. https://doi.org/10.1080/07303084.20 10.10598528

Morales-Belando, M. T., \& Arias-Estero, J. L. (2017). Influence of teaching games for understanding on game performance, knowledge, and variables related to adherence in youth sailing. Journal of Teaching in Physical Education. https://doi.org/10.1123/jtpe.20160024

Nathan, S. (2017). The Effect of Teaching Games of Understanding as a Coaching Instruction had on Adjust, Cover and Heart Rate among Malaysian and Indian Junior Hockey Players. Sports. https://doi.org/10.3390/sports50200 44 
Pill, S. (2011). Teacher engagement with teaching games for understanding game sense in physical education. Journal of Physical Education and Sport.

Rink, J. E., French, K. E., \& Graham, K. C. (1996). Implications for Practice and Research. Journal of Teaching in Physical Education, 15, 490-502.

Sánchez, J. Aguilar, Hernández-Mendo, A., Martínez, I. M., Garrido, R. E. R., \& Ríos, L. J. C. (2018). Effects of a small sided games program on decision making in adolescent girls. Cuadernos de Psicologia Del Deporte.
Sánchez, Javier Aguilar, Tamayo, I. M., \& Ríos, L. J. C. (2016). The assessment in physical education through the "Game Perfomance Assessment Instrument" (GPAI). Estudios Pedagogicos. https://doi.org/10.4067/S071807052016000200001

Serra-Olivares, J., García-López, L. M., \& Calderón, A. (2016). Game-based approaches, pedagogical principles and tactical constraints: Examining games modification. Journal of Teaching in Physical Education. https://doi.org/10.1123/jtpe.20150125 